\title{
Photoregulation of Gold Nanoparticles Stabilized in a Diacetylenic Nanocapsule
}

\author{
Saowalak Somjid, ${ }^{1}$ Apiwat Chompoosor, ${ }^{2,3}$ Somdej Kanokmedhakul, ${ }^{4}$ \\ and Saowapak Teerasong ${ }^{5}$ \\ ${ }^{1}$ Materials Science and Nanotechnology Program and Department of Physics, Faculty of Science, Khon Kaen University, \\ Khon Kaen 40002, Thailand \\ ${ }^{2}$ Nanotec-KKU Center of Excellence on Advanced Nanomaterials for Energy Production and Storage, Khon Kaen 40002, Thailand \\ ${ }^{3}$ Department of Chemistry, Faculty of Science, Ramkhamhaeng University, Bangkok 10240, Thailand \\ ${ }^{4}$ Department of Chemistry and Center of Excellence for Innovation in Chemistry, Faculty of Science, Khon Kaen University, \\ Khon Kaen 40002, Thailand \\ ${ }^{5}$ Department of Chemistry and Applied Analytical Chemistry Research Unit, Faculty of Science, King Mongkut's Institute of \\ Technology Ladkrabang, Bangkok 10520, Thailand
}

Correspondence should be addressed to Apiwat Chompoosor; apiwat@ru.ac.th and Saowapak Teerasong; saowapak.te@kmitl.ac.th Received 16 February 2017; Revised 1 May 2017; Accepted 28 May 2017; Published 28 June 2017

Academic Editor: Paulo Cesar Morais

Copyright (C) 2017 Saowalak Somjid et al. This is an open access article distributed under the Creative Commons Attribution License, which permits unrestricted use, distribution, and reproduction in any medium, provided the original work is properly cited.

The results of releasing a drug in a burst are unpredictable and one of the inherent drawbacks of using nanocarriers. Here, photoresponsive cationic gold nanoparticles to stabilize diacetylenic nanocapsules enabling photoregulated release of payloads are reported. The fabrication of these nanocapsules relied on an electrostatic interaction of a negatively charged diacetylenic core and a positively charged gold nanoparticle shell. Gold nanoparticles with photoresponsive ligands on their surfaces act as both hydrophobic core stabilizers and gatekeepers of the nanocapsules, while their polydiacetylene cores serve as hydrophobic drug carriers that can be tuned using UV irradiation. The morphology of nanocapsules was analyzed using TEM and dynamic light scattering. The resultant nanocapsules had a spherical shape with an average diameter of $152.9 \pm 6.7 \mathrm{~nm}$. Upon UV irradiation, the nanocapsules lost their integrity and an encapsulated model compound was released through diffusion. The release of a hydrophobic molecule was irradiation time dependent and thereby controllable. This light-triggered release provides an alternative strategy for controlled drug delivery.

\section{Introduction}

Nanocapsules provide a number of benefits for anticancer drug delivery due to their high drug loading, ability to preserve drug efficacy, and ease of fabrication [1]. A nanocapsule is a colloidal drug carrier that consists of an oily core coated by a shell [2]. Nanocapsules can have superior properties over other carriers since they have a shell protecting the drug they carry from the environment. So, these drugs have a longer stability and the shell can be further functionalized by attaching targeting agents $[3,4]$. However, release of their payloads in a controllable manner remains a great challenge.
Polydiacetylene (PDA) has gained much attention arising from the added functionality arising from its chemical crosslinking properties [5]. Self-assembly of PDA into various nanostructures including vesicles [6] and micelles [7] was reported. Polydiacetylene nanostructures have a variety of potential applications such as imaging, gene delivery, and drug delivery [8-11]. In drug delivery, PDA can be used for solubilizing hydrophobic drugs with high drug loading. The polymerized units can enhance the stability of this nanocarrier [12].

Recently, nanoparticle stabilized nanocapsules (NSNCs) were devised for use in drug delivery [13] and to deliver a number of payloads including small molecules, protein, 


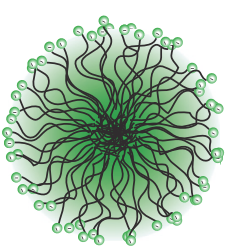

(1) UV at $365 \mathrm{~nm}$, $24 \mathrm{~h}$

(2) Nile red loading

Anionic diacetylene core

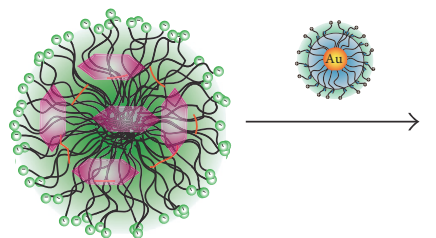

Crosslinked anionic diacetylene core
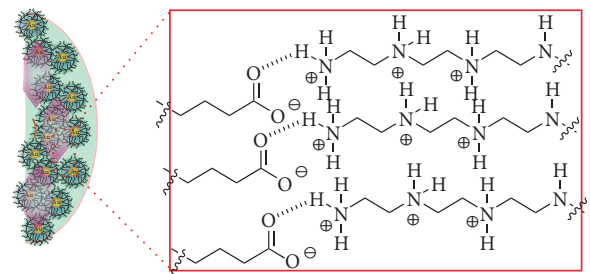

NSNCs

$$
\begin{aligned}
& =\text { nile red }
\end{aligned}
$$

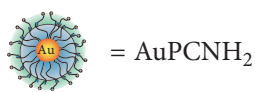

(a)
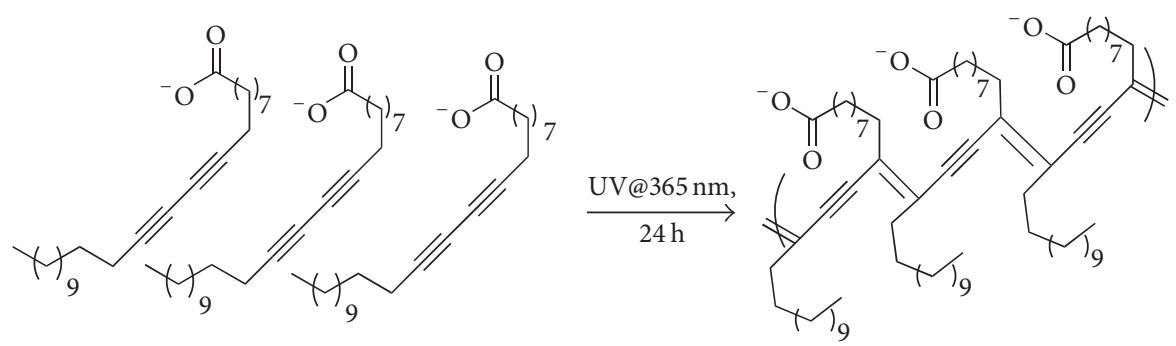

(b)
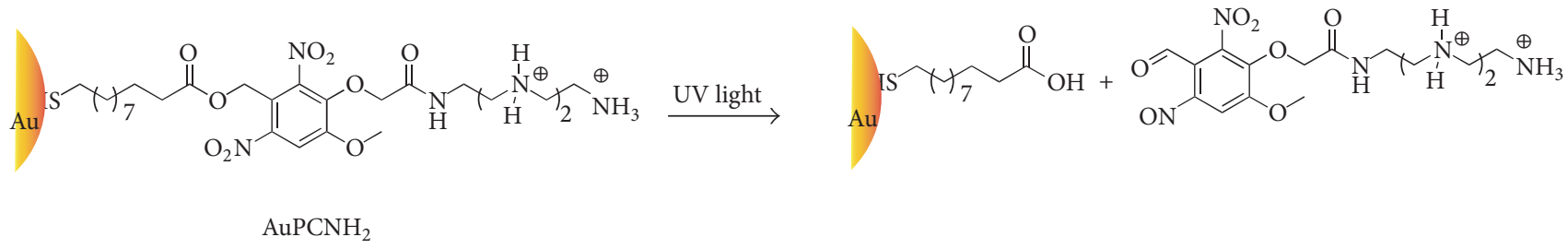

(c)

FIGURE 1: Schematic illustration of (a) formulation of NSNCs through cross-linking of diacetylenic core and nile red loading followed by interfacial assembly of $\mathrm{AuPCNH}_{2}$. (b) Polymerization of polydiacetylenes core initiated by UV irradiation at $365 \mathrm{~nm}$ for $24 \mathrm{hours}$. (c) Chemical structures of $\mathrm{AuPCNH}_{2}$ and its phototriggered cleavage reaction.

and siRNA $[14,15]$. The core of a nanocapsule can be lipids, polymers, and oils [16, 17]. Nanoparticles are used to stabilize the interface between the core and an aqueous exterior environment. Additionally, a nanoparticle at the shell of the NSNCs provides additional features for controlled drug release. For example, nanoparticles can facilitate a controlled release of a drug using a magnetic field [18] or laser light [19]. This property provides a great benefit to the use of nanocapsules. It has drawn our attention to the use of gold nanoparticles with a tailored ligand to regulate the release of an encapsulated model compound.

Herein, we report a facile approach to prepare lightregulated NSNCs consisting of a PDA core and a photocleavable cationic gold nanoparticle $\left(\mathrm{AuPCNH}_{2}\right)$ shell (Figure 1(a)). This selected ligand features three components. An alkyl segment is used to provide particle stability. A photoresponsive o-nitrobenzyl linkage provides a photocleavable property, while the polyamine unit is required to electrostatically interact with the negatively charged PDA. The $\mathrm{AuPCNH}_{2}$ PDA core was stabilized through electrostatic interactions. A PDA core was used to encapsulate a model compound and protect it from degradation. More importantly, the cross-linking properties of the diacetylene moieties imparted a capability to retard the release of an encapsulated drug from the core (Figure 1(b)). Controlled release of encapsulated material was demonstrated in vitro using UV light (Figure 1(c)) [20].

\section{Experimental}

Chemicals, synthesis, and characterization of $\mathrm{AuPCNH}_{2}$ are presented in a previously reported study [21] and supporting information.

2.1. Formulation of a Stabilized Nanocapsule. Twenty (20) mg of 10,12-pentacosadiynoic acid was dispersed in $4 \mathrm{ml}$ of a Tris 
buffer $(\mathrm{pH} \sim 11)$. This solution was sonicated using an ultrasonic probe for about 3 minutes to create a nanoemulsion. The $\mathrm{pH}$ of this solution was 9.97. The resulting diacetylenic emulsion was then exposed to UV light $(365 \mathrm{~nm}, 4 \mathrm{~W})$ for 24 hours to initiate a cross-linked ene-yne. The distance between the solution and the 4-W UV lamp was kept at $5 \mathrm{~cm}$. Thereafter, the resulting solution was filtered through a nylon-syringe filter $(0.45 \mu \mathrm{m})$. Nile red was selected as a model molecule due to its hydrophobic properties and to evaluate the light-responsiveness of the NSNCs. Nile red in $50 \mu \mathrm{l}$ dichloromethane (DCM) $(0.05 \mathrm{mg} / \mathrm{ml})$ was added to the filtered cross-linked diacetylene emulsion $(1000 \mu \mathrm{l})$. The mixture was sonicated again for 3 minutes to homogenize the solution. Then, DCM was removed using a rotary evaporator. After evaporation, $100 \mu \mathrm{l}$ of the mixture was added to $500 \mu \mathrm{l}$ of $\mathrm{AuPCNH}_{2}(2.5 \mu \mathrm{M}$, Figure S1, in Supplementary Material available online at https://doi.org/10.1155/2017/2539520) and stirred for $1 \mathrm{~h}$. The resulting nanocapsules are referred to as NSNCs. These NSNCs were characterized before and after UV irradiation using TEM (FEI Tecnai G2 20) and dynamic light scattering (DLS). In DLS and nanoparticles tracking analysis, $0.3 \mathrm{ml}$ of NSNCs was dispensed in $2.7 \mathrm{ml}$ of Tris buffer. The samples were injected into a folded capillary disposable cell. DLS was measured using a Malvern Zetasizer $^{\mathrm{TM}}$ Nano-ZS. Measurements were made in triplicate at $25^{\circ} \mathrm{C}$ and an average value was reported.

2.2. Release Study of PDA Core and NSNCs without UV Light. An aliquot of $500 \mu \mathrm{l}$ of the resulting NSNCs was pipetted into a cuvette. $2000 \mu \mathrm{l}$ of toluene was added to the NSNCs. The mixture was continuously stirred. The release of nile red was monitored using fluorimetry (JASCO, FP-8200, excitation at $550 \mathrm{~nm}$ and emission at $630 \mathrm{~nm})$. For the release of nile red from the PDA core, $500 \mu \mathrm{l}(0.83 \mathrm{mg} / \mathrm{ml})$ of the crosslinked PDA core was transferred into a cuvette. $2000 \mu \mathrm{l}$ of toluene was then added to the PDA solution. The mixture was continuously stirred and the release of nile red was monitored at 30-minute intervals for 4.5 hours. These experiments were done in triplicate.

\subsection{Release Study of NSNCs Using UV Light. A NSNCs} solution $(100 \mu \mathrm{l})$ was pipetted into a cuvette and exposed to UV light (365 nm, $8 \mathrm{~W}$ ) for various times, that is, $0,5,10$, and $15 \mathrm{~min}$. After irradiation, 2,000 $\mu \mathrm{l}$ of toluene was added to this cuvette. At 30-minute intervals, the release of nile red was monitored using fluorimetry in the same manner described above. These experiments were done in triplicate.

\section{Results and Discussion}

3.1. Formulation of a Diacetylenic PDA Core and Dye Loading. Diacetylenic compounds having both hydrophobic and hydrophilic parts can form emulsions, micelles, and liposomes $[5,6]$. Diacetylene moieties can often cross-link under $\mathrm{UV}$ irradiation at $254 \mathrm{~nm}$ leading to the formation of a conjugated ene-yne sequence [12]. In this work, to maximize the stability of the diacetylenic lipid core and minimize the payloads released from the nanocapsules, a partial crosslinking was devised to incompletely form cross-linkages with a diacetylene core using UV irradiation at $365 \mathrm{~nm}$. After irradiation at $365 \mathrm{~nm}$ for $24 \mathrm{~h}$, the solution turned into a yellowish solution and the absorbance increased between $225 \mathrm{~nm}$ and $350 \mathrm{~nm}$ [12], indicating that the polymerization of ene-yne had taken place (Figure 2(a)). The size of polymerized diacetylenic core was found to be $148.6 \pm 4.6 \mathrm{~nm}$. The partial cross-linkage showed an absorption peak at a lower wavelength than the PDA micelles [12]. This was possibly due to the lower energy used in polymerization, giving rise to a shorter conjugation of ene-yne moieties. Thereafter, loading of nile red was performed using a solvent displacement method [22]. The amount of nile red loaded per nanocapsule was 0.5 wt. $\%$. Encapsulation efficiency (\%EE) of nile red was found to be $95 \%$ using fluorimetry [23].

3.2. Formulation of NSNCs. The charge of the emulsion PDA core and $\mathrm{AuPCNH}$, were measured using a Malvern Zetasizer $\mathrm{s} 90$ at $25^{\circ} \mathrm{C}$. The results showed that the emulsion's PDA core exhibited a negative charge of $-41.76 \pm 2.74 \mathrm{mV}$ and $\mathrm{AuPCNH}_{2}$ had a positive charge of $+41.73 \pm 0.60 \mathrm{mV}$. The negative charge of the emulsion's PDA core was due to carboxylate groups and the positive charge of $\mathrm{AuPCNH}_{2}$ resulting from ammonium groups at the terminus of the ligand. This opposing charge is beneficial for nanocapsule formulation where electrostatic interaction is required between the core and the shell. NSNCs were formulated using an interfacial electrostatic stabilization of a negatively charged PDA droplet and a positively charged $\mathrm{AuPCNH}_{2}$ species. These interactions relied on the attraction of opposing charges and stabilization at the interface between the oily core and the aqueous exterior environment [13]. The optimized ratio of $\mathrm{PDA} / \mathrm{AuPCNH} \mathrm{H}_{2}$ was found by varying the ratio of $\mathrm{PDA} /$ nanoparticles and characterizing the resultant assemblies using TEM. The optimal droplet ratio $\mathrm{PDA} /$ nanoparticle for successful nanoscale NSNC formation was 1: 5 by volume. The shape and size of the NSNCs were characterized using TEM and nanoparticle tracking analysis. In Figure 2(b), TEM images of NSNCs show a spherical shape and smooth edges. An average diameter of $152.9 \pm 67 \mathrm{~nm}$ was observed using nanoparticle tracking analysis (Figure 2(c)). The NSNCs were stable in Tris buffer and media serum with no sign of precipitation.

3.3. NSNCs under UV Irradiation. To test the UV response of the NSNCs, UV irradiation of NSNCs was performed and their morphology monitored using TEM. The NSNCs were suspended in DI water and irradiated with UV light at $365 \mathrm{~nm}$ for 10 minutes. Then, the NSNCs were dispersed onto TEM copper grids. Figure 2(d) shows a loss of spherical integrity of the NSNCs edges. This occurred since the cleavage of the dinitrobenzyl group on $\mathrm{AuPCNH} \mathrm{H}_{2}$ shell had taken place, generating a negative charge on $\mathrm{AuPCNH}_{2}$ (see Figure 1(b)). As a result, charge-charge repulsion possibly occurred. Upon UV irradiation, a nitrobenzaldehyde derivative was released from the gold surfaces. This compound is cytotoxic and can be used to inhibit the proliferation of MDA-MB-231 cells as demonstrated by Anilkumar et al. [24]. 


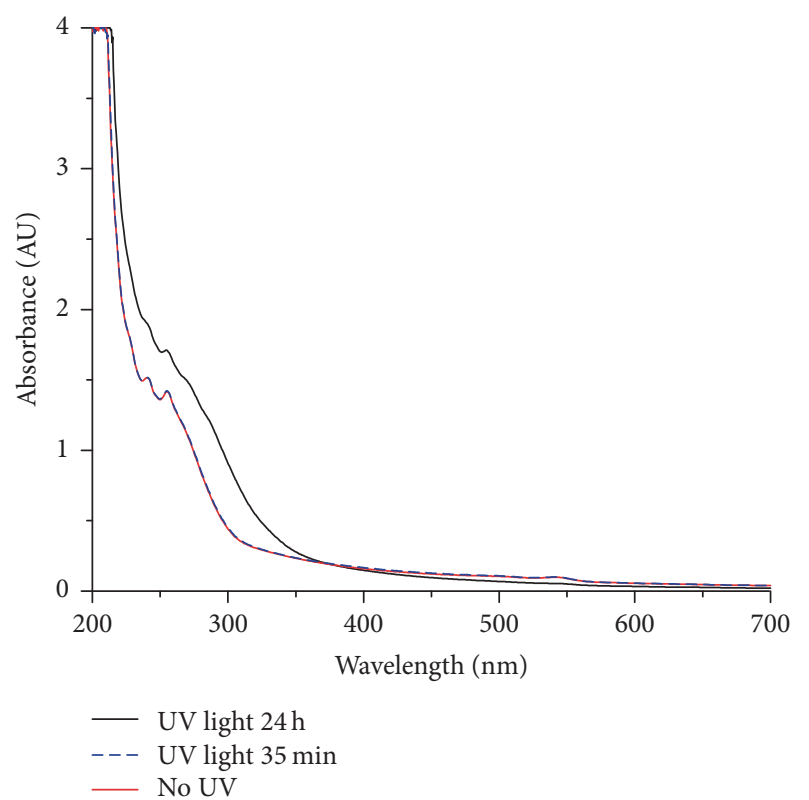

(a)

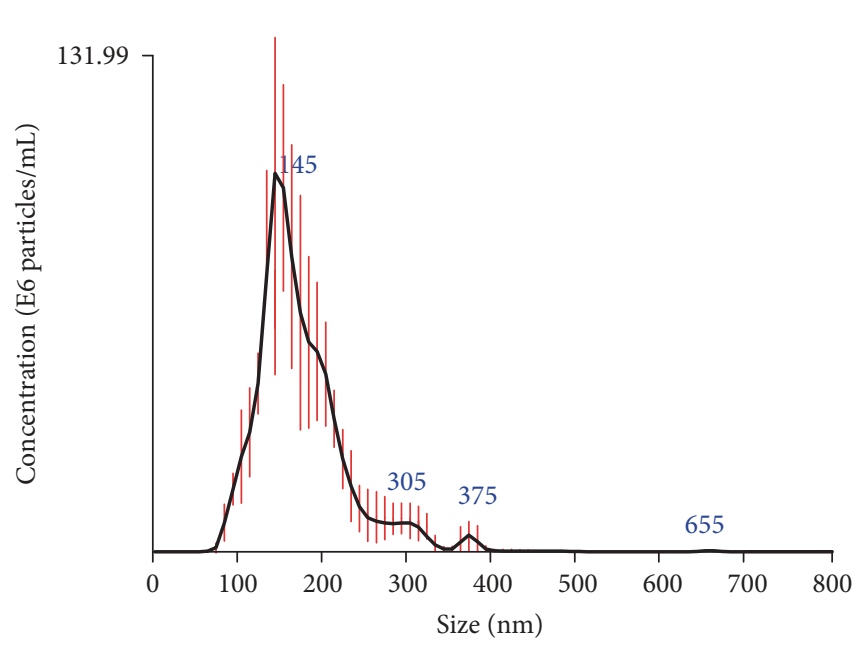

(c)

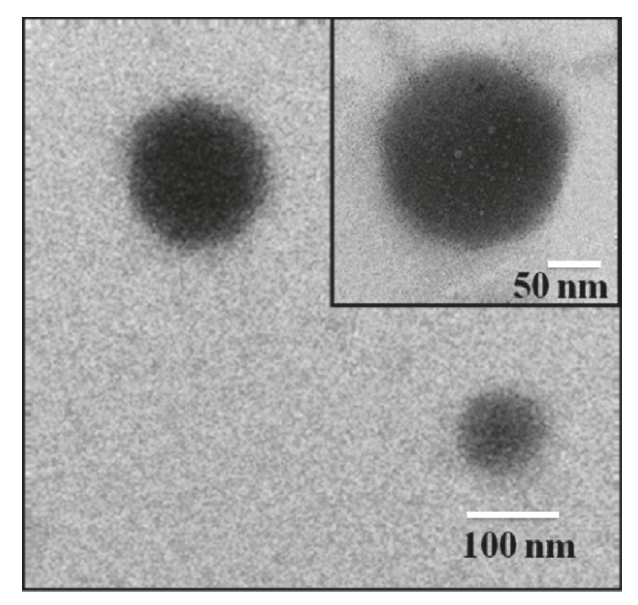

(b)

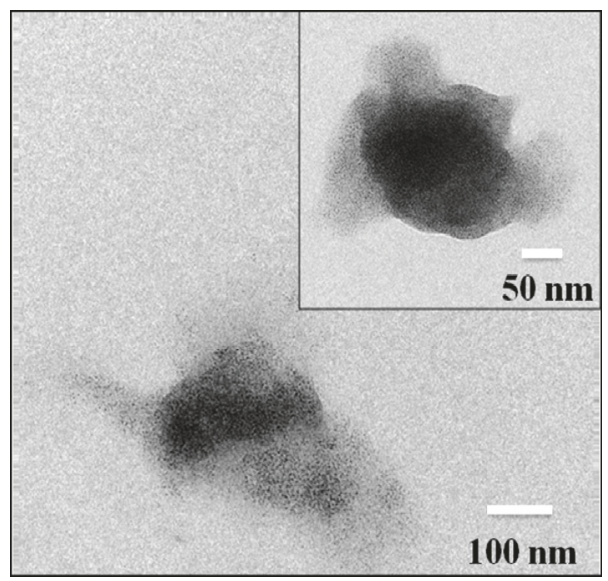

(d)

FIGURE 2: (a) UV-vis spectra of diacetylenic core after UV irradiation at $365 \mathrm{~nm}$ for 24 hours using a handheld UV lamp. (b) TEM images of the NSNCs formed in an emulsion of PDA : AuPCNH $2(1: 5 \mathrm{v} / \mathrm{v})$. (c) Nanoparticle tracking analysis of the NSNCs. (d) TEM images of NSNCs under UV irradiation for 10 minutes.

3.4. Release of Nile Red without UV Irradiation. To validate the role of AuPCNH$H_{2}$ in preventing the release of nile red and the stability of NSNCs in the absence of UV light, the release of emulsions of PDA (core) and NSNCs was examined using a two-phase toluene water system [20, 22]. In Figure 3, a rapid release of nile red was observed from the PDA core. The dye was transported into the toluene phase very quickly and reaching $90 \%$ at 50 minutes. Thereafter, the release leveled off and reached $100 \%$ in 75 minutes. Significantly, in the case of NSNCs, the release of nile red was slower than that from PDA. The dye release was only $\sim 12 \%$ after 50 minutes. The NSNCs had a maximum release of only $40 \%$ after 250 minutes. This result showed that the $\mathrm{AuPCNH}_{2}$ in the shell of NSNCs can prevent the release of nile red from the carrier in the absence of UV light, which is an additional benefit of using $\mathrm{AuPCNH}_{2}$.

3.5. Release of Nile Red upon UV Irradiation. After establishing a formulation method for the NSNCs, we next investigated a light-regulated release of nile red. The model drug release profiles of the NSNCs obtained after various UV irradiation times are presented in Figure 4(a). The release of nile red depended on UV irradiation time. About $70 \%$, $75 \%$, and $80 \%$ of the nile red were released from NSNCs within $6 \mathrm{~h}$ after irradiation for $5 \mathrm{~min}, 10 \mathrm{~min}$, and $15 \mathrm{~min}$, respectively. Release of nile red from NSNCs with no UV light irradiation was around $40 \%$ after 4.5 hours with no initial burst. After UV irradiation, the release showed a two-phase 


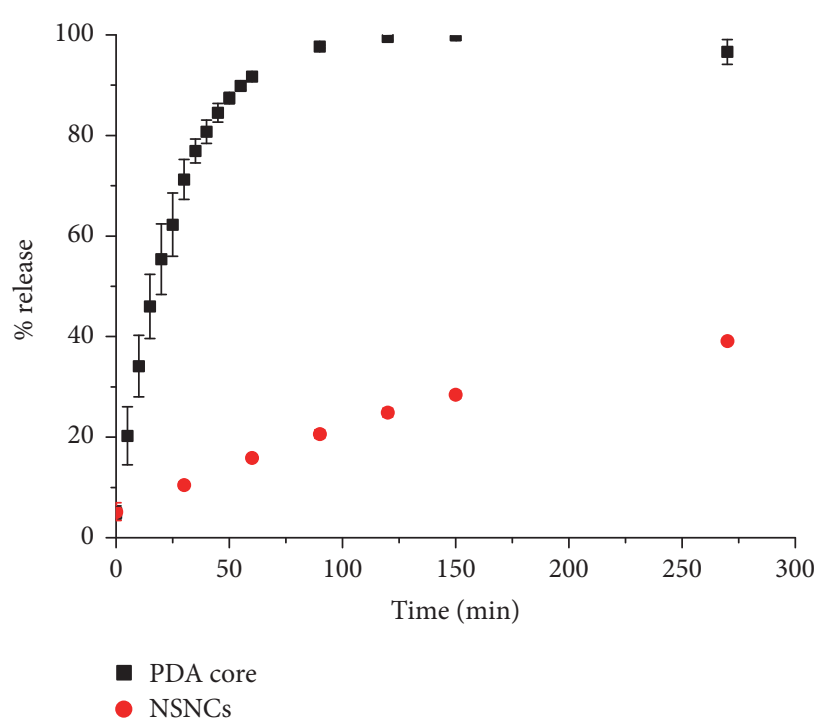

FIGURE 3: Cumulative release profiles of nile red from a PDA core and NSNCs without UV light.

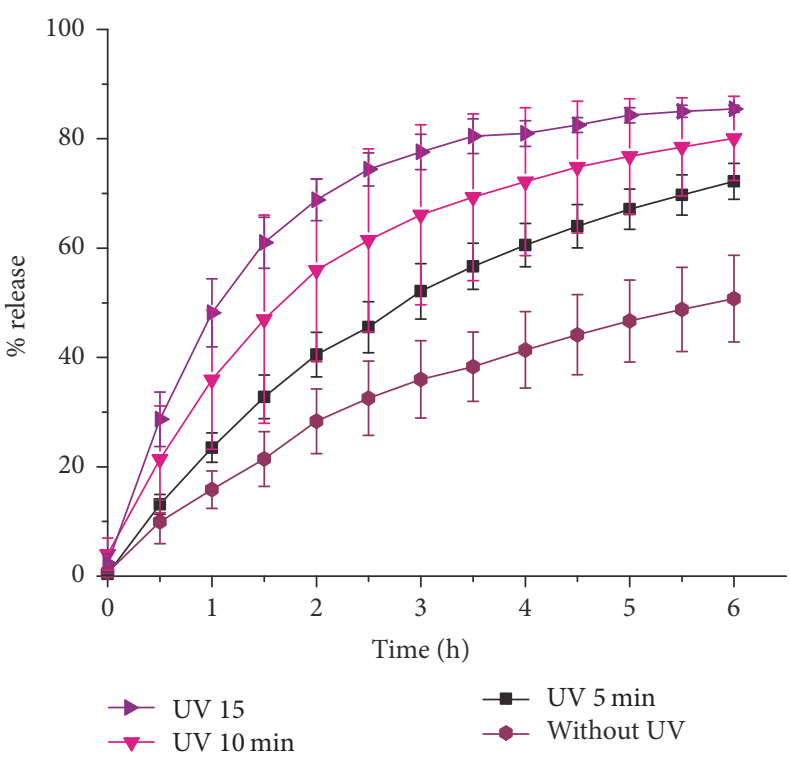

(a)

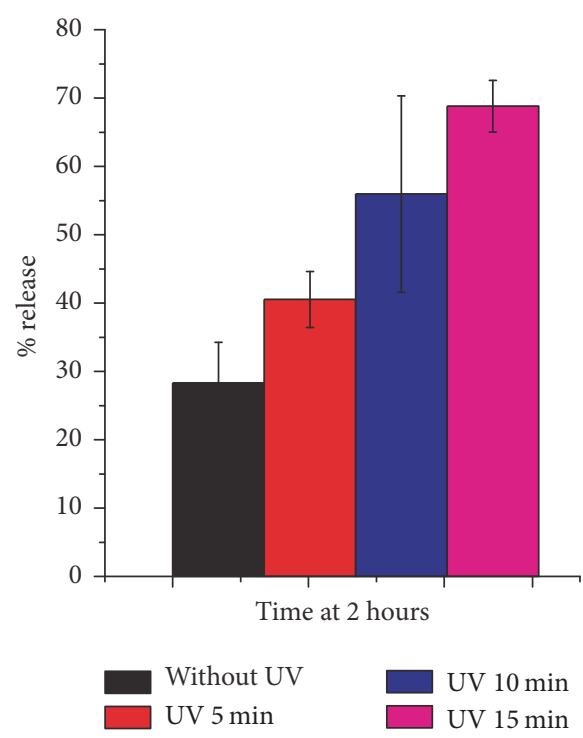

(b)

Figure 4: (a) Cumulative release profiles of nile red from NSNCs after UV irradiation for 0, 5, 10, and 15 minutes and (b) \% release of nile red after 120 minutes with prior UV irradiation for 0, 5, 10, and 15 minutes.

profile, with an initially higher rate of release that thereafter leveled off. Approximately $70 \%$ of the nile red was released from nanocapsules within the first $2 \mathrm{~h}$ after 15 minutes of UV irradiation. This was much faster than that after 10 minutes (55\%) and 5 minutes of UV irradiation (40\%) (Figure 2(b)). The partial cross-linking of diacetylene moieties slowed the release of nile red as compared to the non-cross-linked cores (data not shown). In general, the diffusion of the model drug began in the core and subsequently continued across the shell [17]. The shell played an important rate determining role. In our work, a similar effect was observed. When the shell was cleaved and lost its integrity, release of nile red was seen. Gradual diffusion of nile red was then observed. These results indicated that length of UV irradiation governed the model drug release over time.

\section{Conclusion}

NSNCs were successfully fabricated and used in photoregulated release through electrostatic interactions. These NSNCs had a spherical shape with a $152.9 \pm 6.7 \mathrm{~nm}$ diameter. Additionally, the nanocapsules can protect an encapsulated drug. Their release of a hydrophobic compound can be controlled by varying UV irradiation time. This nanocapsule formulation has potential use in delivery of lipophilic drugs for cancer therapy, as demonstrated in vitro. 


\section{Conflicts of Interest}

The authors declare that they have no conflicts of interest.

\section{Acknowledgments}

Saowalak Somjid would like to thank the Higher Education Research Promotion and National Research University Project of Thailand, Office of the Higher Education Commission, for her M.S. scholarship. Apiwat Chompoosor would like to acknowledge the financial support by The Thailand Research Fund (MRG5980137), the Institute for the Promotion of Teaching Science and Technology (IPST), and the Nanotechnology Center (NANOTEC), NSTDA, Ministry of Science and Technology, Thailand, through its program of Center of Excellence Network.

\section{References}

[1] P. Couvreur, G. Barratt, E. Fattal, P. Legrand, and C. Vauthier, "Nanocapsule technology: a review," Critical Reviews in Therapeutic Drug Carrier Systems, vol. 19, no. 2, pp. 99-134, 2002.

[2] W. He, Y. Lu, J. Qi, L. Chen, F. Hu, and W. Wu, "Nanoemulsiontemplated shell-crosslinked nanocapsules as drug delivery systems," International Journal of Pharmaceutics, vol. 445, no. 1-2, pp. 69-78, 2013.

[3] D. Singodia, S. Talegaonkar, R. K. Khar, and P. R. Mishra, "Novel polymer coupled lipid nanoparticle of paclitaxel with synergistic enhanced efficacy against cancer," Journal of Biomedical Nanotechnology, vol. 7, no. 1, pp. 125-126, 2011.

[4] D. Peer, J. M. Karp, S. Hong, O. C. Farokhzad, R. Margalit, and R. Langer, "Nanocarriers as an emerging platform for cancer therapy," Nature Nanotechnology, vol. 2, no. 12, pp. 751-760, 2007.

[5] I. Theodorou, P. Anilkumar, B. Lelandais et al., "Stable and compact zwitterionic polydiacetylene micelles with tumor-targeting properties," Chemical Communications, vol. 51, pp. 14937-14940, 2015.

[6] Z. Ma and J. Ren, "Fabrication of stable polydiacetylene vesicles with 2,4-akyl-diacetylenic acid," Colloids and Surfaces A: Physicochemical and Engineering Aspects, vol. 303, no. 3, pp. 179-183, 2007.

[7] J.-M. Kim, J.-S. Lee, H. Choi, D. Sohn, and D. J. Ahn, "Rational design and in-situ FTIR analyses of colorimetrically reversibe polydiacetylene supramolecules," Macromolecules, vol. 38, no. 22, pp. 9366-9376, 2005.

[8] E. Gravel, J. Ogier, T. Arnauld, N. MacKiewicz, F. Ducongé, and E. Doris, "Drug delivery and imaging with polydiacetylene micelles," Chemistry - A European Journal, vol. 18, no. 2, pp. 400408, 2012.

[9] E. Morin, M. Nothisen, A. Wagner, and J.-S. Remy, "Cationic polydiacetylene micelles for gene delivery," Bioconjugate Chemistry, vol. 22, no. 10, pp. 1916-1923, 2011.

[10] J. Ogier, T. Arnauld, G. Carrot et al., "Enhanced drug loading in polymerized micellar cargo," Organic and Biomolecular Chemistry, vol. 8, no. 17, pp. 3902-3907, 2010.

[11] N. MacKiewicz, E. Gravel, A. Garofalakis et al., "Tumortargeted polydiacetylene micelles for in vivo imaging and drug delivery," Small, vol. 7, no. 19, pp. 2786-2792, 2011.
[12] A. Perino, A. Klymchenko, A. Morere et al., "Structure and behavior of polydiacetylene-based micelles," Macromolecular Chemistry and Physics, vol. 212, no. 2, pp. 111-117, 2011.

[13] X.-C. Yang, B. Samanta, S. S. Agasti et al., "Drug delivery using nanoparticle-stabilized nanocapsules," Angewandte Chemie International Edition, vol. 50, no. 2, pp. 447-481, 2011.

[14] R. Tang, C. S. Kim, D. J. Solfiell et al., "Direct delivery of functional proteins and enzymes to the cytosol using nanoparticlestabilized nanocapsules," ACS Nano, vol. 7, no. 8, pp. 6667-6673, 2013.

[15] J. Hardie, Y. Jiang, E. R. Tetrault et al., "Simultaneous cytosolic delivery of a chemotherapeutic and siRNA using nanoparticlestabilized nanocapsules," Nanotechnology, vol. 27, no. 37, Article ID 374001, 2016.

[16] E. Glogowski, R. Tangirala, J. He, T. P. Russell, and T. Emrick, "Microcapsules of PEGylated gold nanoparticles prepared by fluid-fluid interfacial assembly," Nano Letters, vol. 7, no. 2, pp. 389-393, 2007.

[17] Z. Jin, Y. Lv, H. Cao et al., "Core-shell nanocarriers with high paclitaxel loading for passive and active targeting," Scientific Reports, vol. 6, Article ID 27559, 2016.

[18] D. A. Gorin, S. A. Portnov, O. A. Inozemtseva et al., "Magnetic/ gold nanoparticle functionalized biocompatible microcapsules with sensitivity to laser irradiation," Physical Chemistry Chemical Physics, vol. 10, no. 45, pp. 6899-6905, 2008.

[19] A. G. Skirtach, A. Muñoz Javier, O. Kreft et al., "Laser-induced release of encapsulated materials inside living cells," Angewandte Chemie - International Edition, vol. 45, no. 28, pp. 46124617, 2006.

[20] K. Sreejivungsa, N. Suchaichit, P. Moosophon, and A. Chompoosor, "Light-regulated release of entrapped drugs from photoresponsive gold nanoparticles," Journal of Nanomaterials, vol. 2016, Article ID 4964693, 7 pages, 2016.

[21] S. S. Agasti, A. Chompoosor, C.-C. You, P. Ghosh, C. K. Kim, and V. M. Rotello, "Photoregulated release of caged anticancer drugs from gold nanoparticles," Journal of the American Chemical Society, vol. 131, no. 16, pp. 5728-5729, 2009.

[22] C. K. Kim, P. Ghosh, C. Pagliuca, Z.-J. Zhu, S. Menichetti, and V. M. Rotello, "Entrapment of hydrophobic drugs in nanoparticle monolayers with efficient release into cancer cells," Journal of the American Chemical Society, vol. 131, no. 4, pp. 1360-1361, 2009.

[23] S. Papadimitriou and D. Bikiaris, "Novel self-assembled coreshell nanoparticles based on crystalline amorphous moieties of aliphatic copolyesters for efficient controlled drug release," Journal of Controlled Release, vol. 138, no. 2, pp. 177-184, 2009.

[24] P. Anilkumar, E. Gravel, I. Theodorou et al., "Nanometric micelles with photo-triggered cytotoxicity," Advanced Functional Materials, vol. 24, no. 33, pp. 5246-5252, 2014. 

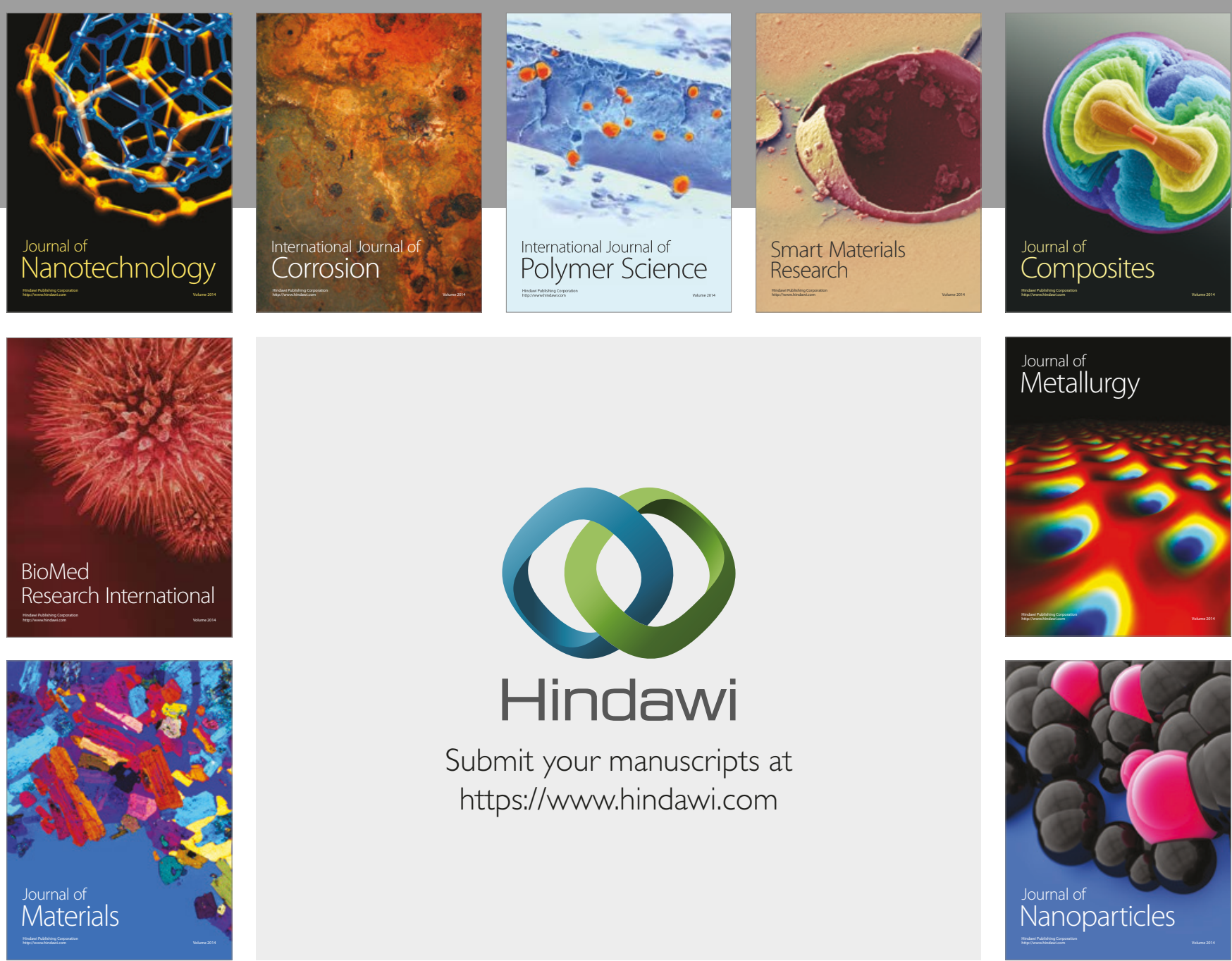

\section{Hindawi}

Submit your manuscripts at

https://www.hindawi.com
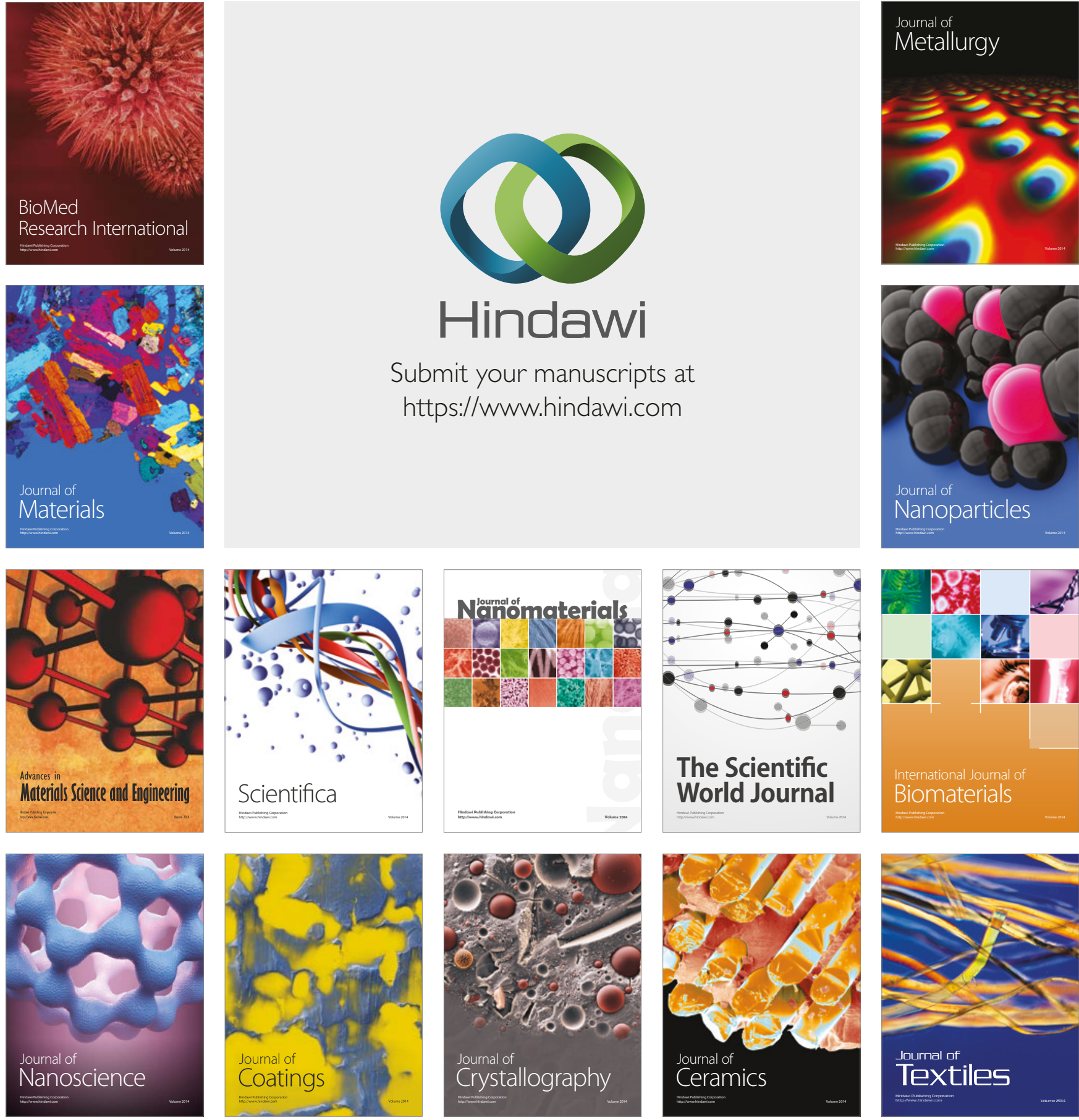

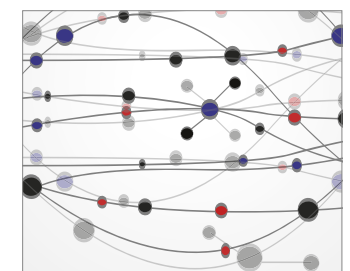

The Scientific World Journal
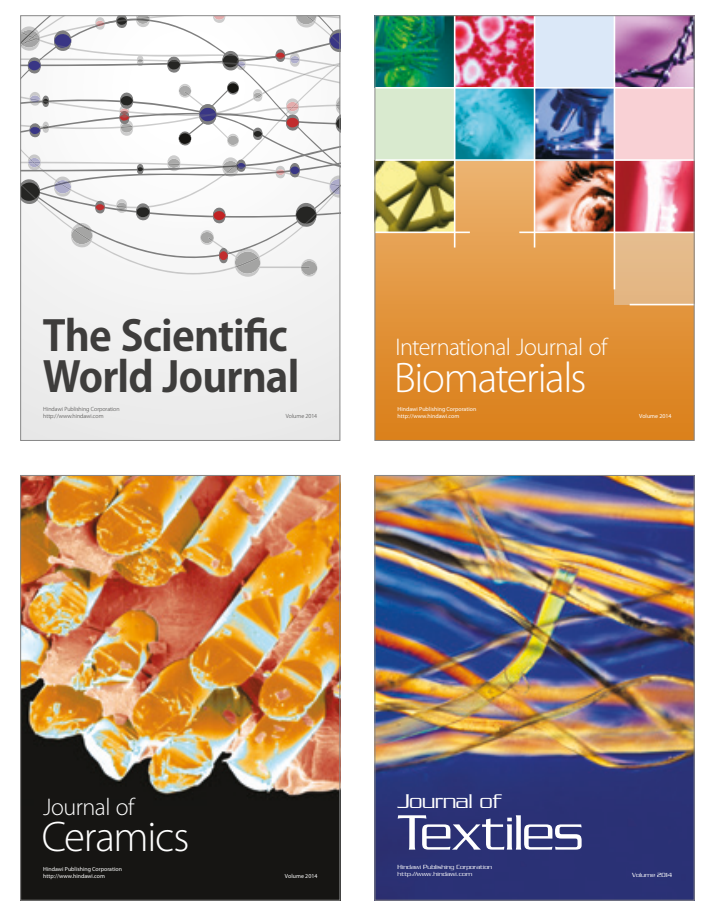